\title{
Incomplete sexual isolation in sympatry between subspecies of the butterfly Danaus chrysippus (L.) and the creation of a hybrid zone
}

\author{
G Lushai ${ }^{1}$, DAS Smith², IJ Gordon ${ }^{3}$, D Goulson ${ }^{1}$, JA Allen ${ }^{1}$ and N Maclean ${ }^{1}$ \\ ${ }^{1}$ Ecology and Biodiversity Division, School of Biological Sciences, University of Southampton, Bassett Crescent East, Southampton SO16 \\ 7PX, UK; ${ }^{2}$ Natural History Museum, Eton College, Windsor SL4 6EW, UK; ${ }^{3}$ nternational Centre for Insect Physiology and Ecology \\ (ICIPE), Box 30772, 00506 Nyayo Stadium, Nairobi, Kenya
}

\begin{abstract}
Subspecies chrysippus, dorippus and alcippus of the butterfly Danaus chrysippus differ at three biallelic colour gene loci. They have partially vicariant distributions, but their ranges overlap over a substantial part of central and East Africa, where hybridism is commonplace. We now report that the West African subspecies alcippus differs from other subspecies, not only in nuclear genotype but also in mitochondrial haplotype in both allopatry and sympatry. The maintenance of concordant nuclear and cytoplasmic genetic differences in sympatry, and in the face of hybridisation, is prima facie evidence for sexual isolation. Other evidence that suggests alcippus may be isolated from chrysippus and
\end{abstract}

dorippus include differences in sex ratio (SR), heterozygote deficiency at one site and deduced differences in patterns of migration. We suggest that, within the hybrid zone, differential infection of subspecies by a male-killing Spiroplasma bacterium causes SR differences that restrict female choice, triggering rounds of heterotypic mating and consequent heterozygote excess that is largely confined to females. The absence of these phenomena from hybrid populations that test negative for Spiroplasma supports the hypothesis. The incomplete sexual isolation and partial vicariance of alcippus suggests that it is a nascent species.

Heredity (2003) 90, 236-246. doi:10.1038/sj.hdy.6800219

Keywords: Danaus chrysippus; heterozygote excess; hybridism; sex-ratio; sexual isolation; Spiroplasma

\section{Introduction}

Danaus chrysippus is a widespread and abundant butterfly that is distributed throughout the Old World tropics in open habitats. In Africa, the species is divided into three largely vicariant subspecies (Talbot, 1943) (Figure 1), alcippus in the western Sahel, south of the Sahara Desert, dorippus in the north-east (northern Kenya and Somalia), and chrysippus (formerly known as aegyptius) in the remaining areas (Owen, 1971; Pierre, 1973; Smith et al, 1997, 1998). We have examined over 15000 specimens of D. chrysippus in European museum collections (Smith et al, 1998) and find that the geographical relation of alcippus and chrysippus (Figure 1) differs profoundly between the two sides of Africa. In the west, there is a clean boundary around $2{ }^{\circ} \mathrm{N}$ that separates the two subspecies, on either side of which hybrids are very rare; alcippus alone occupies West Africa from Senegal to the Camaroun-Gabon border, whence south to the Cape chrysippus is the only form. Even collections from the islands of Fernando Po (off Camaroun) and Saõ Thomé (west of Gabon) are also monomorphic for alcippus and chrysippus, respectively. On the other hand, moving east across the continent towards Ethiopia and Kenya, collections reflect morph-ratio clines, with alcippus being steadily replaced, to the north-east by dorippus and by chrysippus to the south-east. The biogeographical evi-

Correspondence: DAS Smith, Natural History Museum, Eton College, Windsor SL4 6EW, UK. E-mail: d.smith@etoncollege.org.uk

Received 12 June 2002; accepted 26 September 2002 dence suggests that, in the west, equatorial populations of chrysippus and alcippus are parapatric and isolated, whereas, in the east chrysippus and dorippus overlap extensively with one another and with alcippus.

While the partial vicariance of the three subspecies probably reflects past geographical isolation, in Uganda, southern Kenya, Tanzania and parts of several neighbouring countries, but rarely elsewhere, two or more interbreeding polymorphic forms, that match in phenotype their respective subspecies and share their names, are found in sympatry and hybridise (Owen and Chanter, 1968; Smith, 1975a, 1980; Gordon, 1984). The polymorphism is unique among the 157 species of the subfamily Danainae (Ackery and Vane-Wright, 1984); it is, moreover, a surprising feature in an aposematic species that is chemically defended (Rothschild et al, 1975; Brower et al, 1975, 1978; Brown, 1984; JA Edgar in litt. to DASS) and supports numerous mimics (Smith, 1973a, 1976, 1979; Owen and Smith, 1993; Owen et al, 1994). The conundrum would be resolved, however, if there is a recent history of allopatry, with such populations retaining the ability to interbreed without problems. Therefore, the question we address here is whether, despite hybridisation, a given subspecies - we focus on alcippus - is sufficiently isolated from other subspecies to be considered a nascent species.

The formal colour genetics of D. chrysippus (Figure 2) is fairly well known (Owen and Chanter, 1968; Clarke et al, 1973; Smith 1975a, 1980, 1998; Gordon, 1984; Smith et al, 1998). Hindwing colour and pattern are controlled by the autosomal $A$ locus: $2 \mathrm{a}$ and $2 \mathrm{c}$ have the genotype $A A$, 


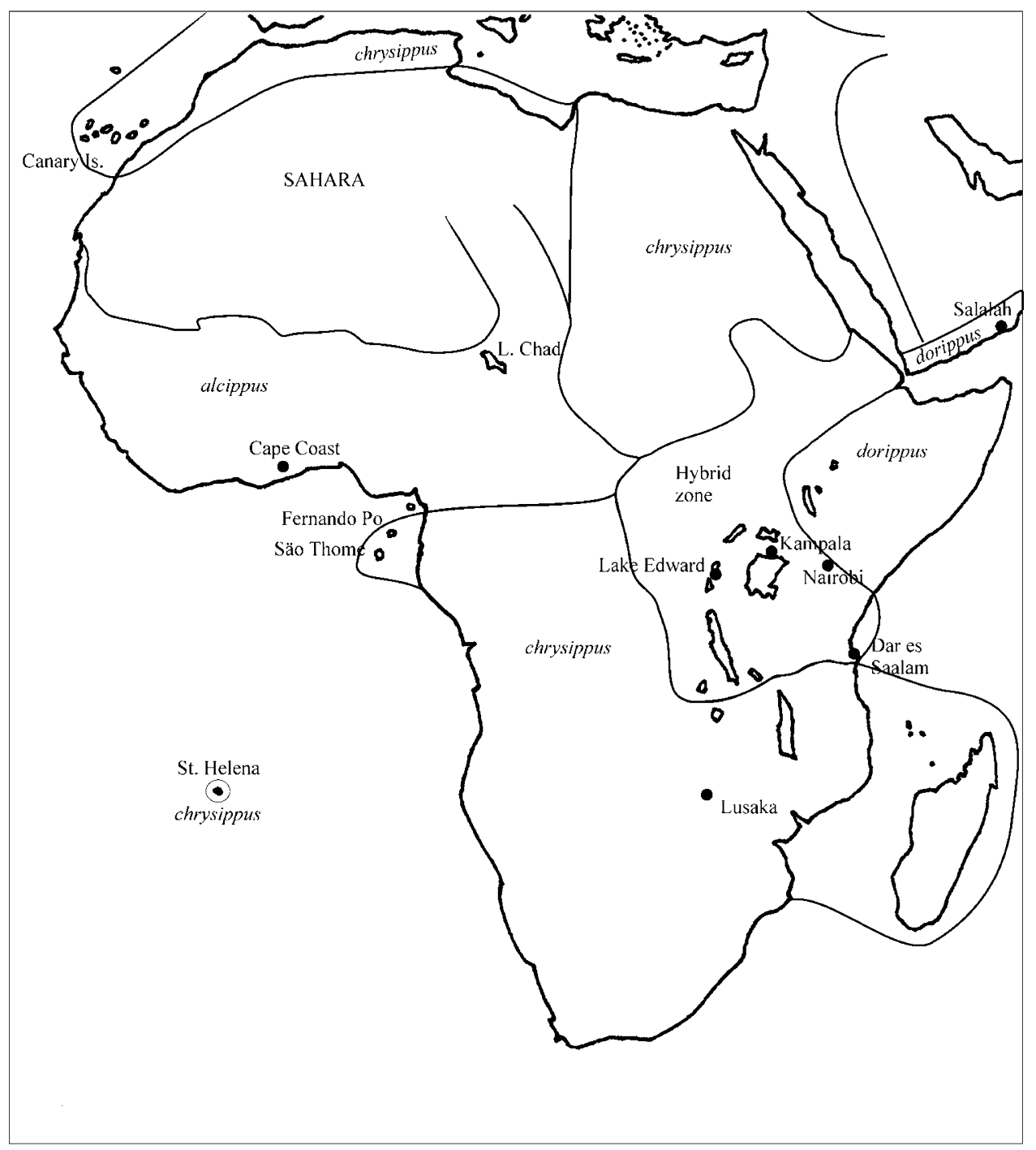

Figure 1 Geographical distribution of the subspecies of D. chrysippus in the Afrotropical region, showing the approximate boundaries of the hybrid zone and locations of sampling sites.

whereas $2 \mathrm{~b}$ and $2 \mathrm{~d}$ are $a a$. Aa heterozygotes are variable being either indistinguishable from $A A$ or showing varied amounts of white (weak alcippus and weak albinus), especially lining the veins, but always less than aa. As heterozygotes of intermediate phenotype occur in both sexes, the possibility that the $A$ locus might be sexlinked (to either sex chromosome) is ruled out, since females would necessarily be hemizygous for the $A$ gene; hence, they would be either $A$ or $a$ in genotype and, in the case of $W$ linkage, polymorphism would be limited to females.

Ground colour is controlled by the $B$ locus with two alleles, brown $(B)$ being variably dominant over orange (b); $B b$ heterozygotes are either brown or, more usually, show a variable extent of brown on the costal and basal areas of the forewing and the basal area of the hindwing, and the remaining areas are orange. The pattern of the forewing apex is governed by the $C$ locus: $2 \mathrm{c}$ and $2 \mathrm{~d}$ are $C C$, whereas $2 \mathrm{a}$ and $2 \mathrm{~b}$ are $c c$. Some $C c$ heterozygotes (transiens) are detectable by a row of pale subapical spots on the forewing underside. The $A$ locus segregates independently (Clarke et al, 1973; Smith, 1975a), whereas the $B$ and $C$ loci are closely linked with a crossover value of $1.9 \%$ in males only (Smith, 1975a).

Despite the ubiquity of hybrids throughout East Africa, three lines of evidence suggest that subspecies of D. chrysippus are, albeit imperfectly, sexually isolated (Smith, 1980).

(1) At Dar es Salaam, Tanzania and Cape Coast, Ghana, orange $(b b)$ and brown $(B-)$ phenotypes mate assortatively (Gordon, 1984; Smith, 1984), as do chrysippus (cc) and dorippus $(\mathrm{C}-$ ) at the former site (Smith, 1975b, 1984). Unfortunately, for the $A$ locus we have no direct evidence for assortative mating, although the field data of Owen and Chanter (1968), tested for randomness of mate choice, are suggestive (exact $P=0.066, n=28$ pairs).

(2) Some, and possibly all, subspecies are independently migratory (Smith and Owen, 1997). Around Nairobi and Dar es Salaam, this behaviour is thought to cause substantial and annually replicated seasonal fluctuation in allele frequencies for the visible $A-C$ loci 
a

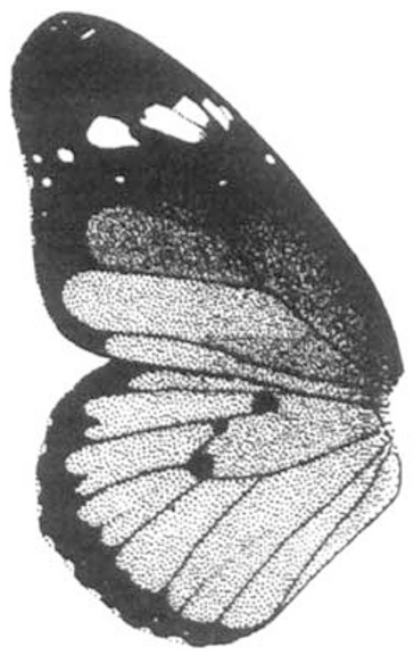

c

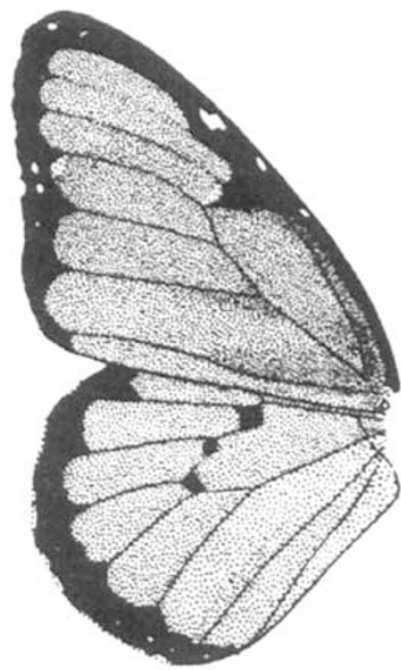

b

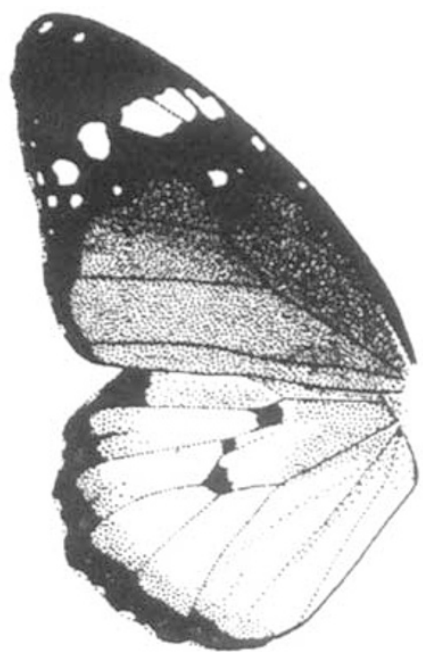

d

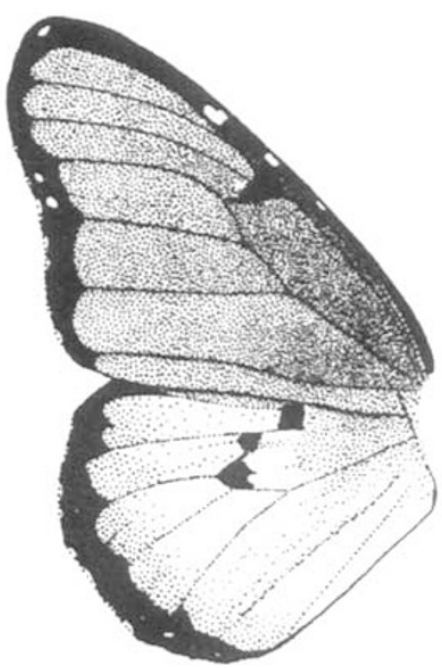

Figure 2 Four major phenotypes of D. chrysippus in Africa: (a) chrysippus, (b) alcippus, (c) dorippus, (d) albinus. The latter is a hybrid phenotype from the cross alcippus $\times$ dorippus. The stippled areas are either tawny orange or nutbrown; the black and white areas are as shown.

(Smith et al, 1997). Some sympatry is now a permanent condition in East Africa. However, if substantial numbers of each subspecies are allopatric at some seasons and sympatric at others, with continuous breeding and 12 or so overlapping generations a year (Owen and Chanter, 1968), punctuated sexual isolation must occur in allopatry. Moreover, although gene flow might extend to all populations, those furthest from the hybrid zone may be isolated by distance (Wright, 1969).

(3) Within the hybrid zone at Kampala, Nairobi, Mombasa and Dar es Salaam, but not reported elsewhere, populations are periodically highly female biased (Owen and Chanter, 1968; Smith, 1975c; Gordon, 1984; Smith et al, 1998; Jiggins et al, 2000; D. Schneider, 1997, in litt. to DASS). The cause is an early male-killing Spiroplasma bacterium inherited as a cytoplasmic gene and imperfectly transmitted vertically down the female line (Jiggins et al, 2000). In Uganda, $40 \%$ of females $(n=90)$ were found to be infected, compared to only $4 \%$ at Watamu on the eastern coast of Kenya. Estimates of infection frequencies elsewhere in East Africa are obtained from the progenies of wild-caught females; Smith et al (1998) reported that $18 \%(n=77)$ of females at
Dar es Salaam, Tanzania, and 69\% $(n=62)$ from Nairobi, Kenya, produced female-biased progenies, predominantly all female broods. On the other hand, small samples of female $D$. chrysippus from Ghana $(n=6)$, South Oman (Salalah) $(n=15)$, South Africa $(n=4)$ and Zambia $(n=3)$ were screened for the presence of Spiroplasma; all tested negative. The Oman result is especially interesting as it is the only sample from a polymorphic site to test negative for Spiroplasma.

Smith (1975b) found a significantly higher frequency of all-female broods from chrysippus compared to dorippus females (Figure 2) at Dar es Salaam. Moreover, in field samples, females predominated among chrysippus, whereas the SR in dorippus was close to $1: 1$. We have drawn attention to heterogeneous SRs within 'morphs' ( $\sim$ subspecies) throughout the hybrid zone (Smith, 1980; Smith et al, 1993, 1997, 1998) and these findings suggest that subspecies may vary in their susceptibility to invasion by Spiroplasma and/or unexplored differences in ecology, behaviour or genetics.

In this paper, we present new $12 \mathrm{~S}$ rRNA mitochondrial gene sequence data and reanalyse $A$ locus genotype (nuclear) data from 10 well-separated populations. Thus, 
we examine congruence between haplotype and nuclear genotype, within and between subspecies, from allopatric and sympatric ranges, for prima facie evidence for sexual isolation. In particular, we investigate concordance, among monomorphic populations and within polymorphic ones, between haplotype and genotype, the latter being the switch between the white hindwinged, western subspecies alcippus (aa), on the one hand, and (chrysippus+dorippus) ( $A A$ ) with orange hindwings, on the other (Figure 2). We review extensive ecological, behavioural and genetic evidence from the hybrid zone, some previously unpublished, that relates to our main hypothesis, namely, that despite much hybridism and long-distance introgression of both cytoplasmic and nuclear genes, there is nevertheless substantial concordance of haplotype and genotype, both within and between populations; this suggests that alcippus may be sexually isolated from (chrysippus+dorippus), not only in allopatry, but also in sympatry.

\section{Methods}

\section{Collection of butterflies}

The new data consist of mitochondrial (mt) DNA sequences, $347 \mathrm{bp}$ fragments of the $12 \mathrm{~S}$ rRNA gene extracted from 10 population samples $(n=169)$ of $D$. chrysippus, eight from the Afrotropical region and two from Asia (Table 1). Butterflies were randomly netted in the field, boxed alive and subsequently killed in ethyl ethanoate vapour, immediately before storage in $95 \%$ ethanol at $-20^{\circ} \mathrm{C}$. Wings were removed and retained in papers for reference.

Unpublished field data for two polymorphic populations, in the Cape Verde Islands and South Oman, are presented here for the first time.

\section{Extraction and amplification of DNA}

DNA was extracted using a salting-out process (Aljanabi and Martinez, 1997). Thoraces were first briefly dried in a vacuum to remove ethanol and then homogenised using UV-crosslinked plastic homogenisers (Scotlab) in the presence of $300 \mu \mathrm{l} 1 \times \mathrm{TEN}(250 \mathrm{mM} \mathrm{NaCl}, 50 \mathrm{mM}$ Tris $\mathrm{HCl}, 10 \mathrm{mM}$ EDTA, $\mathrm{pH}$ 8.0):2\% SDS (9:1) and $30 \mu \mathrm{l}$ of $1 \mathrm{mg} / \mathrm{ml}$ proteinase-K. Homogenised tissue was left overnight at $37^{\circ} \mathrm{C}$ (or for $3 \mathrm{~h}$ at $55^{\circ} \mathrm{C}$ ), after which $100 \mu \mathrm{l}$ of $5 \mathrm{M} \mathrm{NaCl}$ was added, followed by $15 \mathrm{~s}$ vortexing and $10 \mathrm{~min}$ high-speed centrifugation. DNA was precipitated from the supernatant with $1 \mathrm{ml}$ of ice-cold absolute ethanol. Samples were centrifuged at high speed for $10 \mathrm{~min}$ to produce a DNA pellet. Excess ethanol was decanted off and pellets washed twice with $1 \mathrm{ml}$ of $70 \%$ ethanol. After the final wash, all remaining ethanol was removed and the samples air-dried and then resuspended in $50 \mu \mathrm{l}$ of $\mathrm{TE}: \mathrm{HPLC} \mathrm{H}_{2} \mathrm{O}(1: 4)$. Aliquots of genomic DNA were further diluted with $\mathrm{HPLC} \mathrm{H}_{2} \mathrm{O}$ to $25-50 \mathrm{ng} / \mu \mathrm{l}$ for use in polymerase chain reactions. Samples with contaminants that inhibited PCR reactions were divided and one-half was purified in PCR-spin columns (Qiaquick, Qiagen Ltd.), according to the manufacturer's recommendations. This procedure yielded ample DNA for PCR.

The region from the $12 S$ rRNA gene was amplified using primers based on conserved sequences within sites (cf. Simon et al, 1994; Loxdale and Lushai, 1998). Forward
(F) and reverse (R) primers were: $12 \mathrm{~S}$ rRNA-F, $5^{\prime}$ aagagcgacgggcgatgtgt- $3^{\prime}$ and $12 S$ rRNA-R, 5'-aaactaggattagataccctattat- $3^{\prime}$. For PCR reactions, DNA templates were aliquoted in a PCR-reaction mix [0.1v of $10 \times$ Taqpolymerase reaction buffer (Appligene-Oncor), $0.2 \mathrm{mM} /$ $\mu \mathrm{l}$ dNTPs (Pharmacia), $10 \mathrm{pmol}$ primer, $2.0 \mathrm{U}$ Taq DNA polymerase (Appligene-Oncor) in a total volume of $25 \mu \mathrm{l}$ and overlaid with mineral oil]. PCR amplifications were carried out in an Omnigene (Hybaid Ltd.), using a hot start at $94^{\circ} \mathrm{C} / 2 \mathrm{~min}\left(1\right.$-cycle), denaturation at $92^{\circ} \mathrm{C} / 1 \mathrm{~min}$, annealing at $45-58^{\circ} \mathrm{C} / 1 \mathrm{~min}$ (dependent on primer specificity), extension at $72^{\circ} \mathrm{C} / 2 \mathrm{~min}$ (30-cycles) and a final extension step of $72^{\circ} \mathrm{C} / 7 \mathrm{~min}$ (1-cycle). Amplified PCR products were visualized on a $1 \%$ TBE agarose gel and excised gel fragments were purified using gel extraction columns (Qiagen).

\section{Sequencing of DNA}

One template sample from $D$. chrysippus from Malaysia (50 $\mathrm{ng} / \mu \mathrm{l}$ concentrations) was autosequenced for the $12 \mathrm{~S}$ region (Oswell Ltd) in both directions. The sequence was then used as a control for further sequencing. Aliquots of purified PCR fragments were tested on agarose gels for concentration and 50-100 ng of the remaining sample was used in asymmetric reactions with the diluted aliquots of the 'forward primer' $(0.2 \mathrm{pmol})$. Approximately half the reactions were sequenced manually with a cycle sequencing kit (Pharmacia Biotech) and ${ }^{35} \mathrm{~S}$, adopting the dideoxychain-termination procedure (Sanger et al, 1977). These were then visualised by autoradiography. The remaining reactions were carried out in-house using ABI-Big-Dye ${ }^{\mathbb{R}}$ terminator cycle sequencing (Perkin-Elmer).

Both sense and antisense fragments were sequenced. Manual sequences were read into text files by eye and autosequence files were screened by eye using $\mathrm{CHRO}$ MAS 1.45, exported as text files and formatted as interleaved sequences for multiple alignment by CLUSTAL $\times(1.5 b)$ (Thompson et al, 1994). Sequences were also preliminarily screened against GenBank to compare them for sequence homology against known sequences in the BLAST-NR database (eg 98-92\% homology was shown with $12 S$ rRNA sites in Eurema nicippe and Tortricodes alternella (Lepidoptera)).

\section{Results}

12S rRNA haplotypes and their biogeography

Of the 10 populations sampled, five were polymorphic for both haplotype and genotype, and five monomorphic for both (Table 1). All butterflies were readily assigned to either of the two widespread haplotypes, ST (standard) and GH (Ghana), distinguished by a TA/- indel at sites 199-200 (Table 2). The five populations that were monomorphic for colour genes were also invariant for haplotype but 16 minor ST and GH variant haplotypes ( $\leqslant 2 \mathrm{bp}$ differences, $n=19$ individuals) were found in polymorphic populations (Table 2). Although our samples give low geographical coverage for such a vast study area, the existing data suggest that $\mathrm{GH}$ has a western distribution in Africa, whereas ST predominates over the remainder of the continent and extends eastwards across Asia at least as far as Malaysia. 
Table 1 Samples of $D$. chrysippus scored for $A$ locus genotype and sequenced for the $12 \mathrm{~S}$ rRNA mitochondrial gene

\begin{tabular}{|c|c|c|c|c|c|}
\hline \multirow[t]{2}{*}{ Provenance } & \multirow[t]{2}{*}{ Subspecies } & \multirow[t]{2}{*}{ A locus genotypes } & \multicolumn{3}{|c|}{$12 S$ haplotypes } \\
\hline & & & $S T$ & $G H$ & $\mathrm{~N}$ \\
\hline \multicolumn{6}{|l|}{ Monomorphic sites } \\
\hline Cape Coast, Ghana & alcippus & $a a$ & 0 & 15 & 15 \\
\hline Lusaka, Zambia & chrysippus & $A A$ & 8 & 0 & 8 \\
\hline North Oman & chrysippus & $A A$ & 5 & 0 & 5 \\
\hline Petiala, India & chrysippus & $A A$ & 4 & 0 & 4 \\
\hline Penang, Malaysia & chrysippus & $a a$ & 13 & 0 & 13 \\
\hline \multicolumn{6}{|l|}{ Polymorphic sites } \\
\hline Kampala, Uganda & chrysippus, alcippus, dorippus & $A A, A a, a a$ & 12 & 18 & 30 \\
\hline Athi River, Kenya & chrysippus, alcippus, dorippus & $A A, A a, a a$ & 15 & 10 & 25 \\
\hline Masai Mara, Kenya & chrysippus, alcippus, dorippus & $A A, A a, a a$ & 4 & 2 & 6 \\
\hline Dar es Salaam, Tanzania & chrysippus, alcippus, dorippus & $A A, A a, a a$ & 33 & 14 & 47 \\
\hline South Oman (Dhofar) & chrysippus, alcippus, dorippus & $A A, A a, a a$ & 9 & 7 & 16 \\
\hline
\end{tabular}

Notation: ST, standard; GH, Ghana.

Table 2 Variable sites for the $347 \mathrm{bp} 12 \mathrm{~S}$ rRNA sequences included in this paper

\begin{tabular}{|c|c|c|}
\hline Provenance of samples & Haplotype & $\begin{array}{l}0011111222222222 \\
0436889024777889 \\
7529169008089492\end{array}$ \\
\hline
\end{tabular}

Malaysia, India, Zambia, Oman, Kenya, Uganda, Tanzania

Athi River, Kenya

Athi River, Kenya

Athi River, Kenya

Masai Mara, Kenya

Kampala, Uganda

Kampala, Uganda

Dar es Salaam, Tanzania

Dar es Salaam, Tanzania

Salalah, Oman (Dhofar)

Total

Ghana, Uganda, Kenya, Tanzania, Oman

Athi River, Kenya

Masai Mara, Kenya

Kampala, Uganda

Kampala, Uganda

Dar es Salaam, Tanzania

Dar es Salaam, Tanzania

Salalah, Oman (Dhofar)

Total

\begin{tabular}{|c|c|}
\hline ST1 & CT - AAATATCATATAT \\
\hline ST2 & $\ldots \ldots \ldots$ \\
\hline ST3 &. $\mathrm{G}$. \\
\hline ST4 & .AT \\
\hline ST5 & A. . \\
\hline ST6 & . TT \\
\hline ST7 & $\ldots \mathrm{T}$ \\
\hline ST8 & $\ldots \ldots \mathrm{TT}$. \\
\hline ST9 & $\ldots \ldots$ A. . . \\
\hline ST10 & $\ldots \ldots \ldots \ldots$ \\
\hline
\end{tabular}

$\ldots \ldots-\ldots \ldots$

$\ldots \ldots-\ldots \ldots$

$\ldots$. . . . . . .

$\ldots$. . . . .

$\ldots \ldots \mathrm{T}-\ldots \ldots \ldots$

..........A

....... .

A. . . . .

GenBank accession numbers for representative sequences: AF394676-82.

\section{Haplotype and sex}

Within polymorphic populations, the distribution of haplotypes in lumped data differs significantly between the sexes, $\mathrm{GH}$ being predominant $(72.5 \%)$ in males and ST $(71.4 \%)$ in females $\left(\chi_{1}^{2}=5.28, P<0.02\right)$. Although the data are insufficient to show that each sample is individually deviant, the trend lies in the same direction in all five hybrid zone populations ( $P=0.03$, one-tailed). It could be tentatively suggested that ST (chrysippus+dorippus) butterflies are more likely than GH (alcippus) to be infected with male-killing Spiroplasma, although a larger and more extensive sampling programme would be needed to predict its epidemiology within the hybrid zone.

\section{Penetrance of the a allele in Aa heterozygotes}

To establish genotype and allele frequencies at the $A$ locus, without which randomness of mating, HardyWeinberg equilibria (HWE) and concordance between cytoplasmic and nuclear genes cannot be estimated, we needed a better estimate of penetrance of the $a$ allele in Aa heterozygotes than was achieved by Smith (1998). An experienced breeder is readily able to distinguish the heterozygous $A a$ phenotype from $a a$, but not from $A A$ : this is because the $A a$ phenotype ranges from butterflies with a small white patch on the hindwing, through individuals with a scattering of white scales, especially along the margins of veins, to those from which white is absent. Accordingly, we have re-examined the $A a$ 
offspring $(n=294$, Table 3$)$ from $A A \times a a$ and $A a \times a a$ progenies $(n=13)$ from Kenya and Tanzania (Smith et al, 1998); the $a$ allele was scored as penetrant if any white scales were detectable in the relevant area of the hindwing, viewed through a $\times 2$ hand lens. Only progenies obtained from sympatric parents were used because penetrance of $a$ in heterozygotes may differ if the parents are from geographically distant sources. In practice, of course, this distinction may not be strictly sustainable if populations are mobile, with some $A A$ and a a butterflies being cyclically allopatric and sympatric at different seasons, as suggested for $C C$ and $c c$ butterflies by Smith and Owen (1997).

Penetrance of the $a$ allele in $A a$ heterozygotes (Table 4) differs very significantly $(P<0.0001)$ between the sexes. For males penetrance is 0.654 (95\% CI, 0.570-0.738), whereas in females it is only 0.335 (95\% CI, 0.261-0.409). There is no epistatic interaction from either $B$ or $C$ locus that affects this trait. The highly significant interaction between $C$ genotype and sex is a sampling effect, reflecting the predominance of $c c$ among females $(71.1 \%)$ and $C$ - in males $(68.5 \%)$, the majority of the former emanating from all-female broods (Smith et al, 1998). The two marginally significant $B$ locus interac-

Table $32 \times 2 \times 2 \times 2$ contingency table for $A a$ offspring from 13 $A A \times a a$ and $A a \times a a$ progenies raised from wild-caught pairs at Dar es Salaam $(n=9)$ and Nairobi $(n=4)$ (Smith et al, 1998), classified by four criteria, penetrance of the $a$ allele, $B$ locus genotype $(B-/ b b), C$ locus genotype $(C-/ c c)$ and sex

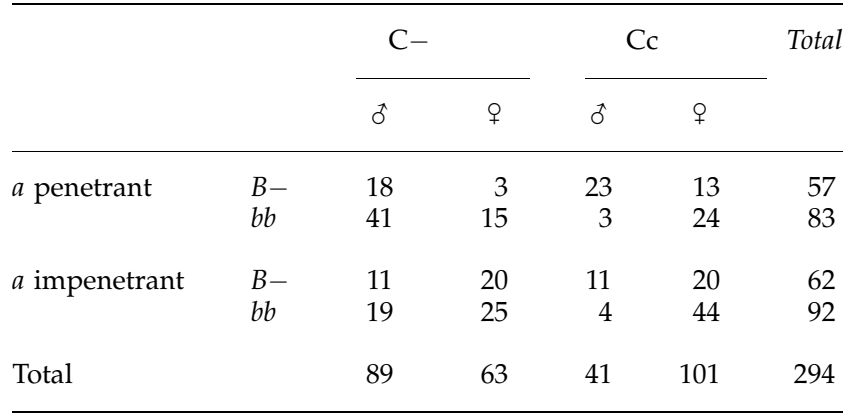

Table 4 Analysis of $\chi^{2}$ for the data in Table 3

\begin{tabular}{lcc}
\hline Effect tested & $\chi^{2}$ & d.f. \\
\hline Penetrance of $a$ allele in & 0.006 & 1 \\
Aa genotype $\times B$ genotype $(B-/ b b)$ & 1.165 & 1 \\
Penetrance of $a$ allele in & & \\
Aa genotype $\times C$ genotype $(C-/ c c)$ & $29.488^{* * *}$ & 1 \\
Penetrance of $a$ allele in $A a$ genotype $\times$ sex & $5.128^{*}$ & 1 \\
$B$ genotype $(B-/ b b) \times C$ genotype $(C-/ c c)$ & $6.168^{*}$ & 1 \\
$B$ genotype $(B-/ b b) \times$ sex & $26.218^{* * *}$ & 1 \\
$C$ genotype $(C-/ c c) \times$ sex & 0.222 & 1 \\
Second-order interaction at $A$ locus & $10.667^{* *}$ & 1 \\
Second-order interaction at $B$ locus & 0.000 & 1 \\
Second-order interaction at $C$ locus & $3.932^{*}$ & 1 \\
Second-order interaction for sex & $10.829^{* *}$ & 1 \\
Third-order interaction & $93.823^{* * *}$ & 11 \\
Total & & \\
\end{tabular}

${ }^{*} P<0.05 ;{ }^{* *} P<0.01 ;{ }^{* *} P<0.001$. Partition of $\chi^{2}$ follows the method of Lancaster (1951) and Lewis (1962). tions, with the $C$ locus and sex, are explained by tight linkage of the $B$ and $C$ loci (Smith, 1975a). The significant second- and third-order interactions are not readily explained.

\section{Concordance between A locus genotype and haplotype is maintained in sympatry}

Concordance of haplotype and $A$ genotype, ST with $A A$ and GH with $a a$, for the vicariant and monomorphic populations in Africa, Arabia and India is 100\% (exact $\left.P=1.0 \times 10^{-9}\right)($ Table 1$)$. Here we should point out that the exception appears to be D. chrysippus in Malaysia, where, except in the northern border province of Kedah, form alcippoides is monomorphic for white hindwing (Corbet et al, 1992; DASS, unpublished) and yet our sample is invariable for ST. As the West African and Malaysian populations are highly disjunct, the recessive $a$ allele may be symplesiomorphic; alternatively, the same mutation may have occurred twice independently. On the other hand, although rare $A a$ hybrids from Kedah resemble those from Africa (DASS, unpublished), confirmation that white hindwing in Malaysia is controlled by the $A$ locus is lacking.

The degree of haplotype-genotype concordance in polymorphic samples from the Afrotropics is set out in Table 5, where the data are presented both uncorrected and corrected for penetrance of the $a$ allele in the $A a$ genotype in males and females. The association of ST with $A$ - and of $\mathrm{GH}$ with $a a$ is highly significant in both cases. For corrected data, $\chi_{2}^{2}=39.2, P<0.0001$, whereas for uncorrected data, $\chi_{2}^{2}=14.6, P<0.001$. Similar tests for association of ST with the $A$ allele and of GH with $a$ are, respectively, for uncorrected and corrected data, $\chi_{1}^{2}=21.9, P<0.001$ and $\chi_{1}^{2}=43.4, P<0.0001$. As the $a$ allele has low frequency in most hybrid zone samples, tests on individual samples show a significant association for haplotype and allele frequencies only at Kampala $\left(\chi_{1}^{2}=8.25, P<0.01\right)$; however, all five hybrid zone samples (Table 1) deviate from randomness in the same direction $(P=0.03$, one-tailed).

The haplotype- $A$ genotype concordance of $\mathrm{GH} / a a$ (alcippus), compared to ST/AA (chrysippus+dorippus), even in conservative tests using data uncorrected for $A a$ genotype frequency, strongly indicates that the subspecies have incomplete sexual isolation in sympatry. Were it otherwise, populations such as these, infected with bacterial symbionts that are inefficiently transmitted vertically, are expected rapidly to lose mtDNA diversity through constant movement of mtDNA variants from infected to uninfected hosts (Hurst et al, 1997). If, however, phenotypes were partially isolated by mate choice, such loss of mtDNA diversity would be forestalled.

\section{Polymorphic populations that have normal sex ratios}

We have new field data, for two polymorphic $D$. chrysippus populations, both of them far distant from East Africa, that have normal (1:1) sex ratios and are, therefore, by deduction probably free from Spiroplasma infection.

On the island of Saõ Vicente, Cape Verde Islands, the D. chrysippus population, sampled in October 2000, is monomorphic $(b b c c)$ at the $B$ and $C$ colour gene loci and polymorphic only for the $A$ gene. The $A$ locus poly- 
Table 5 Frequencies of $12 S$ haplotype, $A$ locus genotype and $A$ locus alleles in polymorphic (hybrid zone) samples of $D$. chrysippus (Frequencies in parentheses are corrected for penetrance of the $a$ allele in the $A a$ genotype.)

\begin{tabular}{|c|c|c|c|c|c|c|c|}
\hline \multirow[t]{2}{*}{ 12S Haplotype } & \multicolumn{4}{|c|}{ A locus genotypes } & \multicolumn{3}{|c|}{ A alleles } \\
\hline & $\mathrm{A}-$ & $\mathrm{Aa}$ & aa & $\mathrm{N}$ & A & a & $\mathrm{N}$ \\
\hline ST & $63(63)$ & $7(7)$ & 3 & 73 & $134(130)$ & $12(16)$ & 146 \\
\hline GH & $29(16)$ & $11(24)$ & 11 & 51 & $69(65)$ & $33(37)$ & 102 \\
\hline Total & $92(79)$ & $18(31)$ & 14 & 124 & $203(195)$ & $45(53)$ & 248 \\
\hline
\end{tabular}

Table 6 Frequencies of $C$ locus phenotypes in a field sample of $D$. chrysippus from Salalah, South Oman, 21-23 October 1998. Figures in parentheses are estimated genotype frequencies after correction for penetrance (Smith, 1998)

\begin{tabular}{lcccc}
\hline & \multicolumn{4}{c}{ C locus phenotypes } \\
\cline { 2 - 5 } & $\mathrm{C}-$ & $\mathrm{Cc}$ & $\mathrm{cc}$ & $\mathrm{N}$ \\
\hline Males & 34 & 16 & 10 & 60 \\
Females & 18 & 6 & 6 & 30 \\
Total & $52(25)$ & $22(49)$ & $16(16)$ & 90 \\
\hline
\end{tabular}

morphism is unexpected and may be recent, since all museum specimens from the Cape Verde Is. we have examined $(n=23)$ are monomorphic for aa (alcippus). Since butterflies on the wing were highly dispersed and difficult to catch, the population was sampled by rearing adults from eggs collected off the foodplant, Calotropis procera. Of 27 adults successfully reared, 15 were female (seven $A a$, eight $a a$ ) and 12 male (three $A a$, nine $a a$ ): thus, there is neither evidence for a female-biased SR $\left(\chi_{1}^{2}=0.33, \mathrm{NS}\right)$, nor for allele frequencies that differ between sexes $\left(\chi_{1}^{2}=0.44\right.$, NS) or heterozygote excess (HE). Indeed, the limited data do not reject a null hypothesis that the population is in HWE $\left(\chi_{1}^{2}=0.15, \mathrm{NS}\right)$. The absence of Spiroplasma is inferred from the $1: 1 \mathrm{SR}$.

More extensive field data were collected for the population at Salalah, South Oman (Table 1) that is monomorphic for $b b$, but polymorphic for both $A$ and $C$ genes. Here, the $a$ allele has a low frequency (0.028) but, since widespread $\mathrm{HE}$ has been found for the $C$ locus throughout East African hybrid populations (Smith et al, 1997), the C polymorphism at Salalah (Table 6) can be used to test the hypothesis that $\mathrm{HE}$ is linked to Spiroplasma infection.

As females $(n=15)$ from this population tested negative for Spiroplasma (Jiggins et al, 2000) and the SR for the field sample is $2: 1$, there are neither grounds to expect a female-biased SR, nor any evidence for it. Furthermore, the frequency distribution of phenotypes between the sexes is not heterogeneous $\left(\chi_{2}^{2}=0.53\right.$, NS), nor do the data, corrected for penetrance of the $c$ allele in the $b b C c$ genotype (Smith, 1998), reject an hypothesis that the population is in HWE at both $C$ locus $\left(\chi_{1}^{2}=1.40, \mathrm{NS}\right)$ and $A$ locus (Table 9). An important caveat here, however, is that the penetrance estimate for $c$ based on
East African material may not be valid for this far-distant population.

\section{Discussion}

We attempt to address two questions. (1) Is the genetic, behavioural and biogeographical evidence relating to subspecies of D. chrysippus, sufficient to suggest that alcippus, in particular, is sexually isolated from other subspecies of the complex and is, thus, a biological species? (2) Is the paradoxical existence of widespread hybridism among subspecies in East Africa a fatal objection to a specific status for alcippus under the biological species concept or, alternatively, is it a maladaptive consequence of the differential invasion of subspecies by male-killing Spiroplasma bacteria that cause severely female-biased SRs and enforce heterotypic mating by infected females?

\section{Sex and $A$ locus allele frequencies}

The samples from Athi River (Tables 7 and 8) suggest that $A$ locus allele frequencies differ significantly between the sexes. Although 'spot' samples at Athi River are variable between months and years (Table 9), all the deviations describe the same trait, the $a$ allele invariably exceeding expectation in females compared to males $(P=0.016)$. The unique sample from Lake Edward (for which we have no haplotype data) is, in this respect, similar to the pooled samples from Athi River. On the other hand, in the Kampala and Dar es Salaam populations, it is the $A$ allele that has a significantly higher than expected frequency in females (Table 7). We may deduce from these data that substantial sex differences for allele frequencies at the $A$ locus are a general feature of all these hybrid zone populations, as previously established for the $B$ and $C$ loci (see Table 8 in Smith et al, 1997). Therefore, as the sexes differ in genetic profile, mate selection must be canalized towards heterotypic pairing. This is especially the case at times when the SR is strongly biased to females, since rare males will overwhelmingly encounter heterotypic females that are denied choice. Thus, as countervailing prezygotic isolation does not prevent eventual copulation, HE is inevitable. HE in three highly female-biased populations (Table 8), two from Athi River and one from Kampala, is effectively confined to females that must be obliged to mate with scarce males, predominantly of different genotype from themselves and from bisexual broods. In a small sample, this scenario was undoubtedly misinterpreted as disassortative mating in a highly 
Table 7 A locus allele counts (expected numbers in parentheses) in males and females from four polymorphic populations of D. chrysippus. Classes that exceed expectation are underlined

\begin{tabular}{|c|c|c|c|c|c|c|}
\hline \multirow[t]{2}{*}{ Population } & \multicolumn{2}{|c|}{ Males } & \multicolumn{2}{|c|}{ Females } & \multirow[t]{2}{*}{$\mathrm{N}$} & \multirow[t]{2}{*}{$\chi_{1}^{2}$} \\
\hline & A & $\mathrm{a}$ & A & $\mathrm{a}$ & & \\
\hline Athi River & $404(382)$ & 96 (118) & $846(868)$ & $290(268)$ & 1636 & $7.71^{* *}$ \\
\hline Lake Edward & $\overline{66}(57)$ & $56(65)$ & $24(33)$ & $\overline{48}(39)$ & 194 & $7.85^{* *}$ \\
\hline Kampala & $\overline{52}(62)$ & 162 (152) & $71(61)$ & $1 \overline{37}(147)$ & 422 & $4.94^{*}$ \\
\hline Dar es Salaam & $4381(4422)$ & $367(326)$ & $29 \overline{21}(2856)$ & $145(201)$ & 7814 & $27.39^{* * *}$ \\
\hline
\end{tabular}

Table 8 Frequencies of $A$ locus genotypes in each sex of D. chrysippus observed\# (expected) in three populations where there is heterozygote excess

\begin{tabular}{|c|c|c|c|c|c|c|}
\hline \multirow[t]{2}{*}{ Sample } & \multirow[t]{2}{*}{ Sex } & \multicolumn{3}{|c|}{ Observed ${ }^{\text {(expected) genotypes }}$} & \multirow[t]{2}{*}{$\mathrm{N}$} & \multirow[t]{2}{*}{$\chi_{1}^{2}$} \\
\hline & & AA & $\mathrm{Aa}$ & aа & & \\
\hline \multirow[t]{2}{*}{ Athi River, 01.86} & $\hat{o}$ & $2(2.4)$ & $3(2.1)$ & $0(0.5)$ & 5 & - \\
\hline & $q$ & $0(10.2)$ & $46(25.7)$ & $6(16.2)$ & 52 & $32.72^{*}$ \\
\hline \multirow[t]{2}{*}{ Athi River, 02.89} & $\hat{o}$ & $12(13.2)$ & $8(6.1)$ & $0(0.7)$ & 20 & - \\
\hline & $q$ & $44(51.8)$ & $69(53.4)$ & $6(13.8)$ & 119 & $10.11^{* *}$ \\
\hline \multirow[t]{2}{*}{ Kampala, 12.91} & $\hat{0}$ & $4(6.4)$ & $44(39.6)$ & $59(61.0)$ & 107 & $1.03 \mathrm{~ns}$ \\
\hline & $q$ & $0(12.1)$ & $71(46.7)$ & $33(45.2)$ & 104 & $21.69^{* * *}$ \\
\hline
\end{tabular}

Notation: not significant; ${ }^{* *} P<0.01 ; * * P<0.001$.

abserved numbers are corrected for penetrance of the $a$ allele in Aa heterozygotes.

Table 9 Goodness-of-fit to Hardy-Weinberg equilibria $\left(H_{0}\right)$ of $A$ locus genotypes in polymorphic populations of $D$. chrysippus

\begin{tabular}{|c|c|c|c|c|c|c|c|c|}
\hline \multirow[t]{2}{*}{ Site } & \multirow[t]{2}{*}{ Date } & \multirow[t]{2}{*}{ Stage collected } & \multirow[t]{2}{*}{ Frequency (q) of a allele } & \multicolumn{5}{|c|}{ Fit of observed genotype frequencies ${ }^{a}$ to $H W E$} \\
\hline & & & & AA & $\mathrm{Aa}$ & aa & $\mathrm{N}$ & $\chi_{1}^{2}$ \\
\hline Athi River & 01.86 & Egg & 0.535 & 2 & 49 & 6 & 57 & $32.00^{* * *}$ \\
\hline Athi River & 01.94/95 & Adult & 0.107 & 88 & 20 & 2 & 110 & $0.02 \mathrm{NS}$ \\
\hline Athi River & 02.89 & Egg & 0.372 & 56 & 77 & 6 & 139 & $30.49^{* * *}$ \\
\hline Athi River & 04.94 & Adult & 0.187 & 144 & 74 & 5 & 223 & $1.85 \mathrm{NS}$ \\
\hline Athi River & 05.87 & Egg & 0.224 & 106 & 53 & 12 & 171 & $2.30 \mathrm{NS}$ \\
\hline Athi River & $07-08.87$ & Egg & 0.309 & 19 & 14 & 5 & 38 & $0.14 \mathrm{NS}$ \\
\hline Athi River & 07.86 & Egg & 0.444 & 4 & 12 & 2 & 18 & $2.57 \mathrm{NS}$ \\
\hline Athi River & 11.86 & Egg & 0.089 & 52 & 9 & 1 & 62 & $0.03 \mathrm{NS}$ \\
\hline Kampala & 12.91 & Adult & 0.707 & 4 & 115 & 92 & 211 & $21.69^{* * *}$ \\
\hline Lake Edward & 09.93 & Adult & 0.536 & 21 & 48 & 28 & 97 & $12.34^{* *}$ \\
\hline Dar es Salaam & $01.74-12.75$ & Adult & 0.067 & 3450 & 402 & 55 & 3907 & $92.88^{* * *}$ \\
\hline Salalah & 10.98 & Adult & 0.028 & 86 & 3 & 1 & 90 & $0.20 \mathrm{NS}$ \\
\hline
\end{tabular}

Notation: as Table 8.

a Observed frequencies are corrected for penetrance of the $a$ allele in the Aa genotype. Genotype numbers in bold and italic type are, respectively, significantly above or below HWE expectation.

female-biased population at Dar es Salaam (Smith, 1973b).

\section{Hardy-Weinberg equilibria (HWE)}

Samples from wild populations (Smith et al, 1997; Table 9) were collected in a number of different ways, each method having its merits and disadvantages for estimating allele frequency, SR and HWE. The majority of Athi River samples consisted of eggs. Most were collected in a single day (with the exception of July-August 1987) and subsequently raised to adults in the laboratory. These samples give the least biased estimates of sex and morph ratios. Samples of flying adults have the disadvantage that the more active males often predominate, even when the population is known to be female biased (eg Kampala, Owen and Chanter, 1968; Dar es Salaam, Smith, 1975b, 1980). In theory, samples could also be biased in other ways such as subspecies differences in migration routines (Smith and Owen, 1997), variation in daily rhythms or microhabitat preferences, although the two latter factors have not yet been investigated. Samples accumulated over long periods, for example, at Dar es Salaam, could in theory show a spurious excess or deficit of heterozygotes resulting from pooling heterogeneous data (Wahlund, 1928). However, as the frequency of the $a$ allele at Dar es Salaam (1972-75) was invariably low 
$(q=0.067,95 \% \mathrm{CI}=0.061-0.073, n=6570)$, and not seasonally variable (Smith et al, 1997), a Wahlund effect can probably be ruled out.

As $D$. chrysippus is both migratory and noted for nonrandom mating, HWE is not to be expected. Although HWE at the $A$ locus may be obtained at Athi River (Table 9), sample sizes are generally inadequate and two of them, January 1986 and February 1989 (Table 8), show that highly significant HE occurs periodically. This phenomenon was also found for the $C$ locus in all Athi River samples except that for January 1986 (Smith et al, 1997). Similar $\mathrm{HE}$ at the $A$ locus is apparent in the Kampala sample that was collected over a period of 2 weeks (Smith et al, 1993). These data show that in heavily female-biased populations (Owen and Chanter, 1968; Smith et al, 1993, 1997, 1998; Jiggins et al, 2000), the excess of $A$ locus heterozygotes may be confined to females (Table 8) that must be predominantly the offspring of mothers infected with Spiroplasma. Thus, if hybridism is effectively confined to one sex, HE is an evolutionary cul$d e$-sac that may impede but will not prevent the evolution of sexual isolation. Indeed, selection should favour chauvinistic males whose preference is for homotypic females that are less likely to carry Spiroplasma. Theoretically, if males are able to detect and mate preferentially with uninfected females, the advantage to the symbiont of infecting more females will be balanced, both by the delay to its host attracting a mate and, possibly, reduced host fecundity (see below).

The long-term work at Dar es Salaam (1974-1975), where $A$ locus gene frequencies are stable, reveals a highly significant heterozygote deficit that suggests either assortative mating or relative heterozygote unfitness. Either outcome supports sexual isolation. The Lake Edward sample, collected in a single day, has an excess of $a a$ and a deficiency of $A A$ that could result either from recent immigration of the former or emigration of the latter.

\section{Dynamics of the East African hybrid zone}

It is now established that the following coincident phenomena are generally encountered in populations of $D$ chrysippus in the East African hybrid zone (Smith et al, 1997, 1998 and references therein): (1) populations are generally heavily female biased; (2) haplotype (this paper) and nuclear gene frequencies differ very significantly between the sexes; (3) heterozygotes may be either in excess, especially among females, or in deficit, and HWE is atypical; (4) 'morphs' differ in migratory behaviour; (5) allele frequencies are subject to marked seasonal variation and (6) paradoxically, although empirical evidence for mate choice suggests it is normally assortative, heterotypic pairing frequently predominates in practice. Applying Occam's razor, we suggest that the co-occurrence throughout an area larger than Western Europe, of six phenomena otherwise unknown in D. chrysippus, most likely share a single explanation.

Whereas previous work has concentrated on the linked $B$ and $C$ loci, we now show that the above phenomena also embrace the unlinked $A$ locus. If future experimental work should confirm that subspecies differ in their susceptibility to invasion by Spiroplasa, differing gene and haplotype frequencies between the sexes in mixed populations would be readily understood. The surfeit of females in an infected subspecies would be forced to mate with males of an uninfected one that has a relatively high SR. As the bacterial gene is passed only down the female line, the preponderance of heterozygotes among females would thus be explained. Furthermore, the associated haplotype of these females would inevitably hitch-hike with the bacterium (Hurst et al, 1997) and the W chromosome (Jiggins et al, 2000). That this has in fact occurred is suggested by the finding that the ST (chrysippus+dorippus) haplotype has a significantly higher frequency $(71.4 \%)$ in hybrid zone females, whereas GH predominates $(72.5 \%)$ in males. As we have never found a wild virgin female, we assume all females, whether infected or not, are eventually mated. However, when males are scarce, they should mate preferentially with uninfected females to produce sons. Furthermore, if uninfected females acquire more spermatophores than infected ones, and the additional nutrient resources are used for egg production, as in D. plexippus (Wells et al, 1993; Zalucki, 1993), males that choose such females could be advantaged by higher fecundity, balanced by greater exposure to shared paternity. D. gilippus females may acquire up to 15 spermatophores (Pliske, 1973) and the closely related $D$. chrysippus is similarly promiscuous (Smith, 1984). Thus, male preference for uninfected over infected females could be tested by spermatophore counts using material typed for Spiroplasma infection.

Our data indicate that, at Kampala and Dar es Salaam, males could in theory preferentially sire bisexual progenies by choosing females that carry a penetrant $a$ allele as this advertises their lower probability of being infected. Similar data suggest that the $b$ and $C$ alleles may also serve, in these and other populations, as advertisements for females less likely to be infected (Smith et al, 1997, 1998). Hence, if homotypic males tend preferentially to choose such females, they will mate assortatively. However, in populations overwhelmingly infected with Spiroplasma, as is the case seasonally at Athi River (Smith et al, 1997), SRs are very low and females will be best served by mating with any available male. In such an event, the majority of pairings will be heterotypic as female choice would be severely limited. The mating behaviour of $D$. chrysippus in the hybrid zone would clearly reward further study.

\section{Polymorphic populations outside East Africa}

The hypothesis that rampant hybridism in East Africa is an enforced consequence of alcippus and (chrysippus+dorippus) being unequally susceptible to Spiroplasma infection has implications for the two populations outside East Africa that are polymorphic at the $A$ locus and probably free from Spiroplasma infection. Sex ratios are predicted to be normal (1:1), mating random, or possibly, by analogy with the $B$ and $C$ loci, assortative, and heterozygote excess absent; furthermore, allele frequencies for an autosomal gene such as $A$ are expected to be equal across the two sexes. In the Cape Verde Islands and Oman, where Spiroplasma is reasonably inferred (from negative tests and/or a 1:1 SR) to be absent, the population parameters we have measured apparently answer these expectations in all respects, although the sample size in the former case is small. Our hypothesis is, therefore, strengthened by finding that 
these two fringe populations, from which the bacterial symbiont is probably absent, are free from all the bizarre phenomena that are normally encountered in East African polymorphic populations.

\section{Conclusions}

Concordance of haplotype and genotype in the partially vicariant subspecies ST/AA (chrysippus+dorippus) and $\mathrm{GH} / a$ a (alcippus), which is imperfectly maintained in the face of extensive hybridism where they meet, suggests that sexual isolation sufficiently robust to withstand periodic introgression has evolved. Mating behaviour at the $A$ locus has not been studied but, as we have good evidence for assortative mating at the $B$ and $C$ loci, is expected. Furthermore, a deficiency of $A$ locus heterozygotes in the 2-year study at Dar es Salaam also supports sexual isolation. The pervasive, but seasonally variable, male-killing Spiroplasma infections, which on present evidence are confined to the East African hybrid zone (Jiggins et al, 2000), are the only known cause of the low SRs and they probably rarely invade all subspecies equally. Therefore, the consequent asymmetry of mate choice, far from being the result of hybridism as suggested by Smith et al (1998), may be its principal causation. On this interpretation, hybridism and HE are maladaptive and arise as disadvantageous side effects of a severely skewed SR. The concordance in alcippus of a diagnostic haplotype and genotype, together with a substantially vicariant distribution, suggest that, despite hybridisation with chrysippus and dorippus where their ranges overlap, it should be treated as a separate species.

\section{Acknowledgements}

We are grateful to the following for financial assistance: Leverhulme Trust Grant F/180/AP to JAA as principal investigator; two Royal Society grants, one to DASS, the other to the late DF Owen, DASS and IJG; Bonhote Bequest, Linnean Society of London to DASS. Dr IJ Saccheri and an anonymous referee made helpful suggestions that have improved the paper. Fred Ansah, Ninian Lowis and Francis Jiggins collected butterflies for us. The late Derek Whiteley drew Figure 1.

\section{References}

Ackery PR, Vane-Wright RI (1984). Milkweed Butterflies. British Museum (Natural History): London.

Aljanabi SM, Martinez I (1997). Universal and rapid saltextraction of high quality genomic DNA for PCR-based techniques. Nucleic Acids Res 25: 4692-4693.

Brower LP, Edmunds M, Moffitt CM (1975). Cardenolide content and palatability of a population of Danaus chrysippus butterflies from West Africa. J Entomol A 49: 183-196.

Brower LP, Gibson DO, Moffitt CM, Panchen AL (1978). Cardenolide content of Danaus chrysippus butterflies from three areas of East Africa. Biol J Linn Soc 10: 251-273.

Brown KS (1984). Adult-obtained pyrrolizidine alkaloids defend ithomiine butterflies against a spider predator. Nature 309: 707-709.

Clarke CA, Sheppard PM, Smith AG (1973). The genetics of fore and hindwing colour in crosses between Danaus chrysippus from Australia and from Sierra Leone (Danaidae). J Lepidopt Soc 27: 73-77.
Nascent speciation and hybridisation in Danaus chrysippus

G Lushai et al

Corbet AS, Pendlebury HM, Eliot JN (1992). The Butterflies of the Malay Peninsula, 4th edn. Malayan Nature Society: Kuala Lumpur.

Gordon IJ (1984). Polymorphism of the tropical butterfly Danaus chrysippus L. in Africa. Heredity 53: 583-593.

Hurst GDD, Hurst LD, Majerus MEN (1997). Cytoplasmic sexratio distorters. In: O'Neill SL, Hoffman AA, Werren JH (eds) Influential Passengers: Inherited Microorganisms and Arthropod Reproduction. Oxford University Press: Oxford. pp 125-154.

Jiggins FM, Hurst GDD, Jiggins CD, Schulenburg JHGVD, Majerus MEN (2000). The butterfly Danaus chrysippus is infected by a male-killing Spiroplasma bacterium. Parasitology 120: $439-446$

Lancaster HO (1951). Complex contingency tables treated by the partition of $\chi^{2}$. JR Statist Soc B 13: 242-249.

Lewis BN (1962). On the analysis of interaction in multidimensional contingency tables. JR Statist Soc 125: 88-117.

Loxdale HD, Lushai G (1998). Molecular markers in entomology. Bull Ent Res 88: 577-600.

Owen DF (1971). Tropical Butterflies. Clarendon Press: Oxford.

Owen DF, Chanter DO (1968). Population biology of tropical African butterflies. 2. Sex ratio and polymorphism in Danaus chrysippus L. Rev Zool Bot Afr 78: 81-97.

Owen DF, Smith DAS (1993). Danaus chrysippus and its polymorphic Müllerian mimics in Tropical Africa (Lepidoptera:Nymphalidae: Danainae). Trop Lepidoptera 4: 1-5.

Owen DF, Smith DAS, Gordon IJ, Owiny AM (1994). Polymorphic Müllerian mimicry in a group of African butterflies: a re-assessment of the relationship between Danaus chrysippus, Acraea encedon and Acraea encedana (Lepidoptera: Nymphalidae). J Zool Lond 232: 93-108.

Pierre J (1973). Etude du polymorphisme chez Danaus chrysippus L. (Lépidoptère: Danaïde): aires du répartition et catégories infraspécifiques en Afrique. CR Acad Sci, Paris (D) 276: 2685-2687.

Pliske TE (1973). Factors determining mating frequencies in some New World butterflies and skippers. Ann Entomol Soc Am 66: 164-169.

Rothschild M, Von Euw J, Reichstein J, Smith DAS, Pierre J (1975). Cardenolide storage in Danaus chrysippus with additional notes on D. plexippus. Proc Roy Soc Lond B 190: $1-31$.

Sanger F, Nicklen S, Coulson AR (1977). DNA sequencing with chain-terminating inhibitors. Proc Natl Acad Sci USA 74: 5463-5467.

Schneider D (1987). The strange fate of pyrrolizidine alkaloids. In: Chapman R, Bernays E, Stoffolano J (eds) Perspectives in Chemoreception and Behavior. Springer-Verlag: Heidelberg. pp 123-143.

Simon C, Frati F, Beckenbach A, Crespi B, Liu H, Flook P (1994) Evolution, weighting, and phylogenetic utility of mitochondrial gene-sequences and a compilation of conserved polymerase chain-reaction primers. Ann Entomol Soc Am 87: 651701.

Smith DAS (1973a). Batesian mimicry between Danaus chrysip pus and I (Lepidopters) in Tanzania. Nature 242: 129-131.

Smith DAS (1973b). Negative non-random mating in the polymorphic butterfly Danaus chrysippus in Tanzania. Nature 242: 131-132.

Smith DAS (1975a). Genetics of some polymorphic forms of the African butterfly Danaus chrysippus L. (Lepidoptera: Danaidae). Entomol Scand 6: 134-144.

Smith DAS (1975b). Sexual selection in a wild population of the butterfly Danaus chrysippus L. Science 187: 664-665.

Smith DAS (1975c). All-female broods in Danaus chrysippus L. and their ecological significance. Heredity 34: 363-371.

Smith DAS (1976). Phenotypic diversity, mimicry, and natural selection in the African butterfly Hypolimnas misippus. Biol J Linn Soc 8: 183-204.

Smith DAS (1979). The significance of beak marks on the wings of an aposematic, distasteful and polymorphic butterfly. Nature 281: 215-216. 
Smith DAS (1980). Heterosis, epistasis and linkage disequilibrium in a wild population of the polymorphic butterfly Danaus chrysippus. Zool J Linn Soc 69: 87-109.

Smith DAS (1984). Mate selection in butterflies: competition, coyness, choice and chauvinism. In: Vane-Wright RI, Ackery PR (eds). The Biology of Butterflies. Symposia of the Royal Entomological Society of London 11. Academic Press: London. pp 225-244.

Smith DAS (1998). Non-Mendelian segregation and variable penetrance of colour genes in the polymorphic butterfly Danaus chrysippus (L.). Heredity 80: 474-480.

Smith DAS, Gordon IJ, Depew LA, Owen DF (1998). Genetics of the butterfly Danaus chrysippus (L.) in a broad hybrid zone, with special reference to sex ratio, polymorphism and intragenomic conflict. Biol J Linn Soc 65: 1-40.

Smith DAS, Owen DF (1997). Colour genes as markers for migratory activity: the butterfly Danaus chrysippus in Africa. Oikos 78: 127-135.

Smith DAS, Owen DF, Gordon IJ, Lowis NK (1997). The butterfly Danaus chrysippus (L.) in East Africa: polymorphism and morph-ratio clines within a complex, extensive and dynamic hybrid zone. Zool J Linn Soc 120: 51-78.

Smith DAS, Owen DF, Gordon IJ, Owiny AM (1993). Polymorphism and evolution in the butterfly Danaus chrysippus (L.) (Lepidoptera: Danainae). Heredity 71: 242-251.
Talbot G (1943). Revisional notes on the genus Danaus Kluk (Lep. Rhop. Danaidae). Trans Roy Ent Soc Lond 93: 115-148.

Thompson JD, Higgins DG, Gibson TJ (1994). CLUSTAL X: improving the sensitivity of progressive multiple sequence alignment through sequence weighting, positions-specific gap penalties and weight matrix choice. Nucleic Acids Res 22: 4673-4680.

Wahlund S (1928). Zusammensetzung von Populationen und Korrelation-serscheinumgen vom Standpunkt der Vererbungslehre aus betrachet. Hereditas 11: 65-106.

Wells H, Wells PH, Rogers SH (1993). Is multiple mating an adaptive feature of monarch butterfly winter aggregation? In: Malcolm SB, Zalucki MP (eds) Biology and Conservation of the Monarch Butterfly. Natural History Museum of Los Angeles County: Los Angeles. pp 61-68.

Wright S (1969). Evolution and the Genetics of Populations. Vol 2. The Theory of Gene Frequencies. Chicago University Press: Chicago.

Zalucki MP (1993). Sex around the milkweed patch - the significance of patches of host plants in monarch reproduction. In: Malcolm SB, Zalucki MP (eds) Biology and Conservation of the Monarch Butterfly. Natural History Museum of Los Angeles County: Los Angeles. pp 69-76. 